\title{
Use of bovine pregnancy-associated glycoproteins to predict late embryonic mortality in postpartum Nelore beef cows
}

\author{
K.G. Pohler ${ }^{\mathrm{a}, 1}$, R.F.G. Peres ${ }^{\mathrm{b}}$, J.A. Green ${ }^{\mathrm{a}}$, H. Graff ${ }^{\mathrm{c}}$, T. Martins ${ }^{\mathrm{b}}$, \\ J.L.M. Vasconcelos ${ }^{\mathrm{d}}$, M.F. Smith ${ }^{\mathrm{a}, *}$ \\ ${ }^{a}$ Division of Animal Sciences, University of Missouri, Columbia, Missouri, USA \\ b Aluno do Programa de Pós Graduação em Zootecnia da Faculdade de Medicina Veterinária e Zootecnia-UNESP, Botucatu, \\ São Paulo, Brazil \\ ${ }^{\mathrm{c}}$ Agropecuária Fazenda Brasil, Barra do Garças, MT, Brazil \\ d Departamento de Produção Animal, Faculdade de Medicina Veterinária e Zootecnia-UNESP, Botucatu, São Paulo, Brazil
}

\section{A R T I C L E I N F O}

\section{Article history:}

Received 19 October 2015

Received in revised form 12 January 2016

Accepted 27 January 2016

\section{Keywords:}

Bovine

Pregnancy

Embryonic mortality

Pregnancy-associated glycoproteins

\begin{abstract}
A B S T R A C T
The primary objective was to determine if circulating concentration of bovine pregnancyassociated glycoproteins (bPAGs) on Day 30 after artificial insemination (AI) may serve as a marker of late embryonic mortality in Bos indicus (Nelore) beef cows. In experiment 1, postpartum Nelore beef cows $(n=56)$ were artificially inseminated at a fixed time (Day 0 ) after synchronization of ovulation. Serum samples were collected on Days 0,21, 24, 27, and 30 after AI. The first significant increase $(P<0.0001)$ in serum bPAGs after insemination occurred on Day 24 of gestation. In experiment 2, ovulation was synchronized in postpartum Nelore beef cows $(n=1460)$ and AI was received at a fixed time. Pregnancy diagnosis and blood sample collection were carried out on Days 28 to 30 after insemination. Cows that maintained a pregnancy from Days 28 to 100 of gestation $(n=714)$ had significantly $(P<0.0001)$ higher circulating concentrations of bPAGs on Day 28 compared with cows that did not maintain a pregnancy (embryonic mortality [EM]) until Day $100(\mathrm{n}=89)$. When Day 28 bPAG concentration was included in a logistic regression model to predict pregnancy maintenance until Day 100 of gestation, there was an increase $(\mathrm{P}<0.0001)$ in the probability of maintaining pregnancy as maternal concentrations of bPAGs increased. A receiver operating characteristic curve was generated to determine bPAG concentrations on Day 28 that should predict embryonic survival or mortality with an accuracy of $95 \%$ or more. On the basis of the positive and negative predicative value analysis, at Day 28 of gestation a circulating concentration of bPAGs greater than $7.9 \mathrm{ng} / \mathrm{mL}$ was $95 \%$ accurate in predicting embryonic maintenance (to Day 100); a concentration of bPAGs less than $0.72 \mathrm{ng} / \mathrm{mL}$ was $95 \%$ accurate in predicting EM by Day 100 . In experiment 3 , the preceding model was tested in a separate set of Nelore beef cows to validate whether bPAGs would serve as an accurate measure of late embryonic mortality. Ovulation was synchronized in 650 Nelore cows and received AI at a fixed time. Pregnancy diagnosis and bPAG sampling were performed at Day 28 of gestation. Only pregnant cows were included in the analysis. On the basis of the previously reported bPAG cutoff values, the test was $95 \%$ accurate in predicting late embryonic mortality at Day 28 of gestation. In summary, bPAGs seem to be a good marker for predicting EM between Days 28 and 100 of gestation and suggest that this model could help dissect the molecular mechanisms leading to late EM.
\end{abstract}

(c) 2016 Elsevier Inc. All rights reserved.

\footnotetext{
* Corresponding author. Tel.: +1 573882 8239; fax: +1 5738847827.

E-mail address: Smithmf@missouri.edu (M.F. Smith).

${ }^{1}$ Present address: Department of Animal Science, The University of Tennessee, Knoxville, Tennessee, USA.
} 


\section{Introduction}

In the US, the annual cost of reproductive failure to the beef industries is estimated to be $\$ 600$ million. The exact causes of the preceding reproductive failure include animal management issues, cow infertility, bull infertility, heat stress, and embryonic mortality. Embryonic mortality is thought to be a primary contributor to this loss [1]. During gestation embryonic mortality can occur either early (before Day 28 of gestation) or late (after Day 28 of gestation). Reports of high fertilization rates after a single insemination ( $\sim 90 \%$ of ovulated oocytes), followed by pregnancy rates of $60 \%$ to $70 \%$ on Day 28 in cows indicate that early embryonic mortality may be $20 \%$ to $30 \%$ in beef cows [2,3]. In addition, after Day 28 of gestation late embryonic mortality has been reported to vary from $3.2 \%$ to $42.7 \%$ [4-11]. The large variation in the incidence of late embryonic mortality may be because of differences in cytoplasmic maturity of the oocyte at ovulation, inadequate preovulatory concentrations of estradiol, reduced postovulatory luteal progesterone secretion, inadequate uterine environment, placental insufficiency, and (or) the source of embryos (in vivo fertilized, in vitro fertilized, or cloned by somatic cell nuclear transfer). Cytoplasmic maturity of the oocyte, source of embryos, and placenta sufficiency may affect placental function, whereas preovulatory estradiol, luteal progesterone secretion, and inadequate dialogue between the embryo and maternal environment may affect endometrial function [12-15].

Significant effort has been directed toward understanding the factors causing early embryonic mortality; however, relatively little is known about the causes or mechanisms associated with late embryonic mortality, much of which occurs around the time of placentome formation (Days 35-40 of gestation). Although the incidence of late embryonic mortality is normally less than that of early embryonic mortality, the economic consequences of late embryonic mortality can be significant because late embryonic mortality can cause a prolonged delay in conception date and increases cows culled at the end of the breeding season [7]. Previously it has been shown that bovine pregnancyassociated glycoprotein (bPAGs) may serve as a marker of late embryonic mortality in beef and dairy cattle [16-19]. However, in all the preceding studies Bos taurus beef and dairy cows were used; thus, little is known about these relationships in Bos indicus cattle. The objectives of these experiments were to characterize basic bPAG profiles early in gestation and determine whether bPAGs were an accurate predictor of late embryonic mortality in these cattle.

\section{Materials and methods}

Experiments were conducted in a commercial beef farm located in Mato Grosso, Brazil in accordance with the Guide for the Care and Use of Agricultural Animals in Agricultural Research and Teaching [20]. In all experiments cows were maintained on pastures, specifically Brachiaria brizantha with water and mineral salt ad libitum. Cows used in all three experiments below were at least 25 days postpartum when the estrus synchronization protocol began. All cows received an intravaginal progesterone (P4) insert containing $1.9 \mathrm{~g}$ of P4 (CIDR; Zoetis, São Paulo, Brazil), and $2.0 \mathrm{mg}$ (im) estradiol benzoate (2.0 mL of estrogen; Farmavet, São Paulo, SP, Brazil) on Day -11, CIDR withdrawal, $25 \mathrm{mg}$ (im) dinoprost tromethamine (PGF; 5.0 mL of Lutalyse; Zoetis, Brazil), 300 iu of equine chronic gonadotropin, and $1.0 \mathrm{mg}$ (im) of estradiol cypionate ( $0.5 \mathrm{~mL}$; Zoetis, Brazil) on Day -2, and fixed-time artificial insemination (TAI) on Day 0. After TAI, all cows were diagnosed for pregnancy at Days 28 to 30 of gestation. Pregnancy determination was based on the presence of a viable embryo (presence of a heartbeat) as detected by ultrasound scan. After confirmation of pregnancy, a blood sample was collected for quantification of bPAG. All cows were then confirmed pregnant at Day 100 of gestation.

\subsection{Animals, treatment, and procedures}

\subsubsection{Experiment 1}

Postpartum Nelore beef cows $(n=56)$ were artificially inseminated at a fixed time after synchronization of ovulation (Day 0) by using the protocol described previously. Before TAI on Day 0, the size of the ovulatory follicle was also determined by ultrasound. Serum samples were collected on Days $0,21,24,27$, and 30. All samples were harvested by venipuncture into a $10-\mathrm{mL}$ vacutainer tube and allowed to clot at room temperature for 1 hour before being placed in a $4{ }^{\circ} \mathrm{C}$ refrigerator for 24 hours. After centrifugation, serum was collected and stored at $-20^{\circ} \mathrm{C}$ until measurement of bPAGs was performed.

\subsubsection{Experiment 2}

Synchronization of estrus and TAI in postpartum Nelore beef cows ( $n=1460$ ) was conducted as described. In this experiment, there were both primiparous $(n=240)$ and multiparous cows $(n=1220)$. A subset of the cows $(n=720)$ was artificially inseminated at a fixed time with semen from eight Angus sires ( $n=90$ cows per sire) to assess the effects of sire on pregnancy rate after TAI and Day 28 bPAG concentrations. All other cows were randomly assigned to be inseminated with semen from Angus sires of proven fertility. Serum samples were collected from all cows on Day 28 after insemination as explained in experiment 1 .

\subsubsection{Experiment 3}

Ovulation was synchronized in primiparous postpartum Nelore beef cows $(n=689)$ as described previously and received TAI on Day 0 . Cows were inseminated randomly from Angus sires of proven fertility. In addition, Estrotect heat detector patches were scored on a scale of 0 to $4(0$, lost patch; $1,<25 \%$ activated; $2,<50 \%$ activated; $3,<75 \%$ activated; and $4,>75 \%$ activated). Serum samples were collected from all cows on Day 28 after insemination as explained in experiment 1 .

\subsection{Assays}

Serum concentrations of progesterone were quantified by RIA with Coat-a-Count RIA kit (Diagnostic Products Corporation, Los Angeles, CA) as described previously $[21,22]$. Intra-assay coefficient of variation was $5 \%$ and the assay sensitivity was $0.08 \mathrm{ng} / \mathrm{mL}$ for the progesterone RIA. Serum concentrations of bPAGs were determined by a monoclonal-based bPAG ELISA similar to that described by 
Green et al. [23] and used previously to monitor bPAGs $[18,24]$. Each assay was run with a standard curve, a sample from a pregnant cow from Day 60 of gestation and a pooled sample from a nonpregnant cow.

\subsection{Statistical analysis}

One-way ANOVA (SAS 9.4) was used to test differences among Day 28 circulating concentrations of bPAGs for beef cows undergoing TAI that maintained pregnancy and those that established a pregnancy, but did not maintain it. The LOGISTIC procedure in SAS (9.4; SAS Institute Inc., Cary, NC) was used to determine the probability of pregnancy maintenance based on a single Day 28 serum concentration of bPAG. Receiver operating characteristic (ROC) curves were generated with the MedCal software package, setting embryonic mortality as the "true positive." After the generation of an ROC, the resulting true positive and false positives were subjected to positive and negative predictive value analysis to determine a concentration of bPAGs on Day 28 , below which $95 \%$ of cows would experience embryonic loss by Day 100 . Analysis of breakpoints was conducted by using PROC NLIM [25] in SAS and was used to determine the first significant change in the slope of the line.

\section{Results}

\subsection{Experiment 1}

Overall pregnancy rate after TAI was $39 \%(n=22)$, and on the basis of break point analysis, the first significant increase (Fig. 1; $\mathrm{P}<0.0001$ ) in bPAG concentration occurred at Day 24 of gestation. In addition, there was no significant effect of ovulatory follicle size $(P=0.44)$ at Day 0 on circulating concentrations of bPAGs at Day 28 or any relationship between circulating $\mathrm{P} 4(\mathrm{P}=0.37)$ and bPAG concentrations on Day 28.

\subsection{Experiment 2}

The Day 28 pregnancy rate was 55\% ( $\mathrm{n}=803$ ); pregnancy was confirmed based on a viable fetal heartbeat

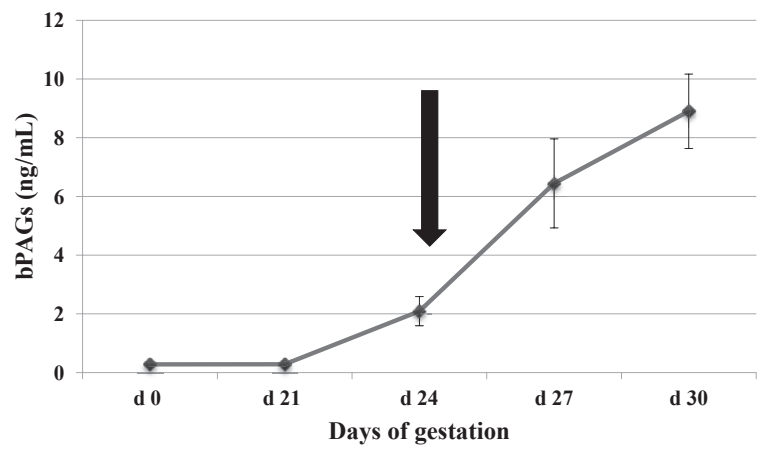

Fig. 1. Serum concentrations of bovine pregnancy-associated glycoproteins (bPAGs) in pregnant Nelore cows (mean \pm SEM; $n=22$ ) from Days 0 to 30 of gestation in experiment 1 . First significant increase $(P<0.0001)$ in circulating bPAG concentrations occurred on Day 24 of gestation. Arrow head represents the first significant increase in circulating bPAG concentrations.

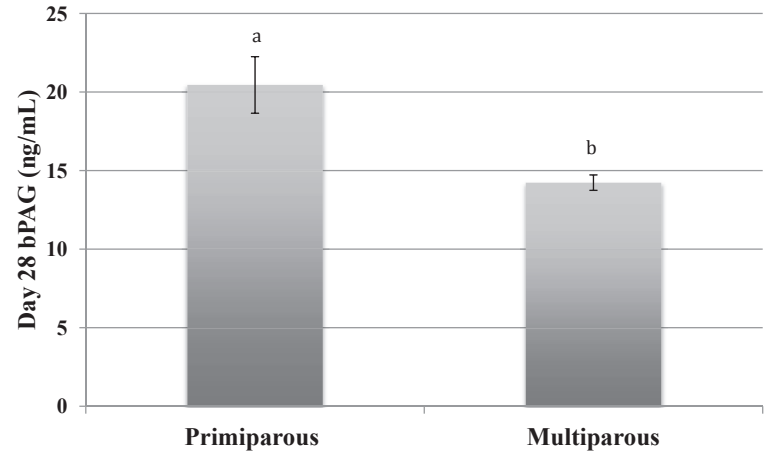

Fig. 2. Serum concentrations of bPAGs (mean \pm SEM) in postpartum pregnant Nelore beef cows (primiparous, $n=116$; multiparous, $n=687$ ), which received TAI on Day 0 and had a viable embryo on Day 28 of gestation. Primiparous Nelore beef cows had increased $(\mathrm{P}<0.05)$ circulating concentrations of bPAGs on Day 28 compared with multiparous cows independent of body weight. a,b denote a significant difference.

visualized by transrectal ultrasonography. The average serum concentration of bPAGs on Day 28 was $15.11 \pm 9.92 \mathrm{ng} / \mathrm{mL}$ (mean $\pm \mathrm{SD}$ ). Serum concentrations of bPAGs were higher (Fig. 2; P $<0.03$ ) in primiparous cows $(\mathrm{n}=116 ; 20.45 \pm 1.80 \mathrm{ng} / \mathrm{mL}$; mean $\pm \mathrm{SEM})$ compared with multiparous cows $(\mathrm{n}=687 ; 14.23 \pm 0.49 \mathrm{ng} / \mathrm{mL}$; mean \pm SEM). There was no relationship between body weight and bPAG concentrations across all cows tested. In addition, cows that maintained a pregnancy from Days 28 to 100 of gestation ( $\mathrm{n}=714$ ) had significantly (Fig. 3; $\mathrm{P}<0.0001$ ) higher circulating concentrations of bPAGs on Day 28 of gestation compared with cows that did not maintain a pregnancy (embryonic mortality) until Day 100 $(\mathrm{n}=89$ ). When Day 28 bPAG concentration was included in a logistic regression model to predict pregnancy maintenance until Day 100 of gestation, there was an increase (Fig. 4; $\mathrm{P}<0.0001$ ) in the probability of maintaining pregnancy until Day 100 of gestation as maternal concentrations of bPAGs increased. To conduct a more stringent

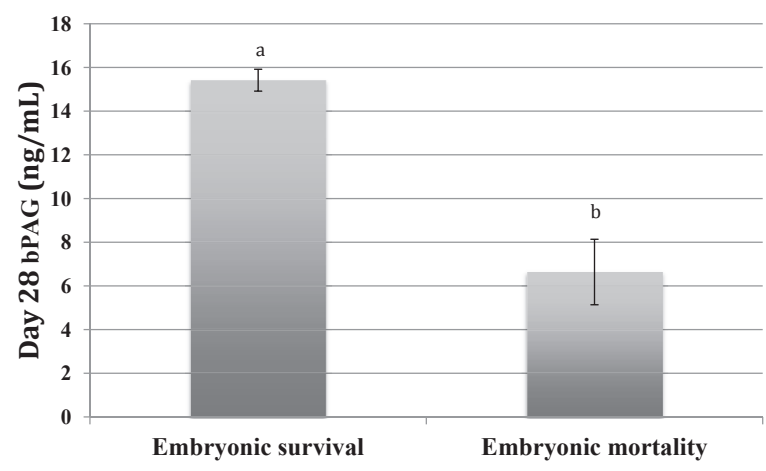

Fig. 3. Serum concentrations of bPAGs (mean \pm SEM) in postpartum Nelore beef cows that received TAI on Day 0 and had a viable embryo on Day 28 of gestation $(\mathrm{n}=803$ ) and either maintained (embryonic survival; $\mathrm{n}=714$ ) or experienced embryonic mortality $(n=89)$ by Day 100 . Nelore cows that experienced late embryonic mortality by Day 100 of gestation had decreased $(\mathrm{P}<0.05)$ circulating concentrations of bPAGs on Day 28 compared with cows that maintained an embryo until Day 100. a,b denote a significant difference. 


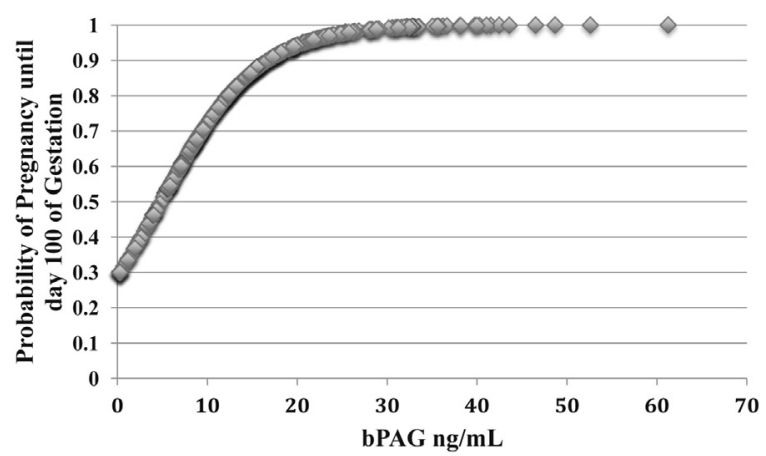

Fig. 4. Probability of pregnancy maintenance after TAI between Days 28 and 100 of gestation based on Day 28 serum concentrations of bPAGs $(\mathrm{n}=803)$. Increased serum concentrations of bPAGs on Day 28 significantly increased $(\mathrm{P}<0.05)$ the probability of pregnancy maintenance until Day 100 of gestation in Nelore beef cows after TAI.

test of the effectiveness of a single circulating bPAG concentration to predict embryonic survivability and/or mortality, an ROC (Fig. 5) curve was generated to determine bPAG concentrations on Day 28 that should predict embryonic survival or mortality with an accuracy of $95 \%$ or more. On the basis of the positive and negative predicative value analysis, a circulating concentration of bPAGs greater than $7.9 \mathrm{ng} / \mathrm{mL}$ was $95 \%$ accurate in predicting embryonic maintenance (until Day 100) and a concentration of bPAGs

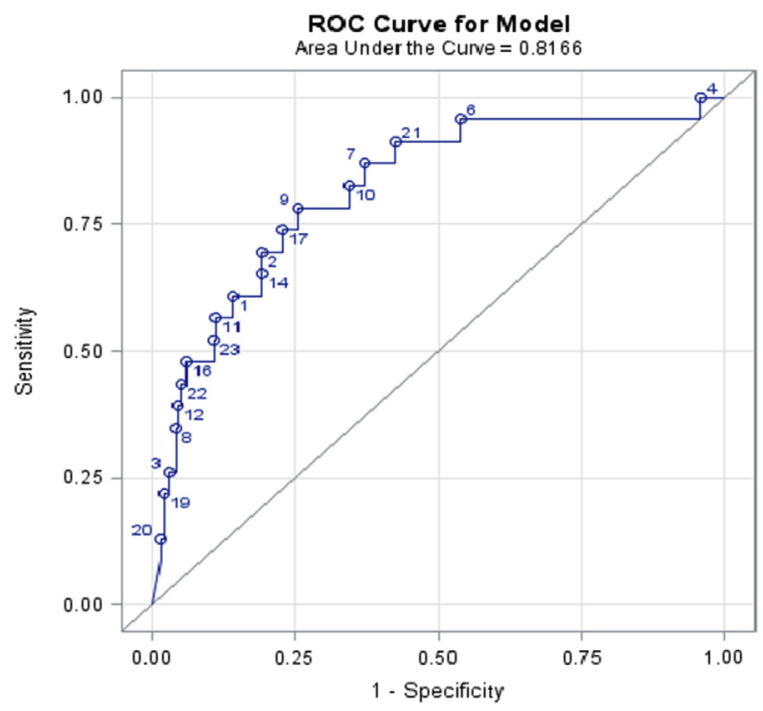

Fig. 5. Receiver operating curve (ROC) using Day 28 circulating concentrations of bPAGs to model embryonic mortality between Days 28 and 100 of gestation in Nelore beef cows after TAI. A serum concentration of bPAG less than $0.72 \mathrm{ng} / \mathrm{mL}$ resulted in a $95 \%$ confidence that embryonic mortality would occur between Days 28 and 100 of gestation with an area under the curve of $81.6(\mathrm{P}<0.05)$. The ROC curve graphically displays the relationship between true-positive rate (sensitivity) and false-positive rate (1-specificity) when an increasing cutoff value for the bPAG test was used. When the truepositive rate and the false-positive rate both decrease as the cutoff value is increased, this results in a diagonal line through the center meaning the test is not predictive (50:50 probability). However, when the line is deflected to the left of center the test is useful because it has a relatively high true positive rate and a low false positive rate at a specific cutoff value.

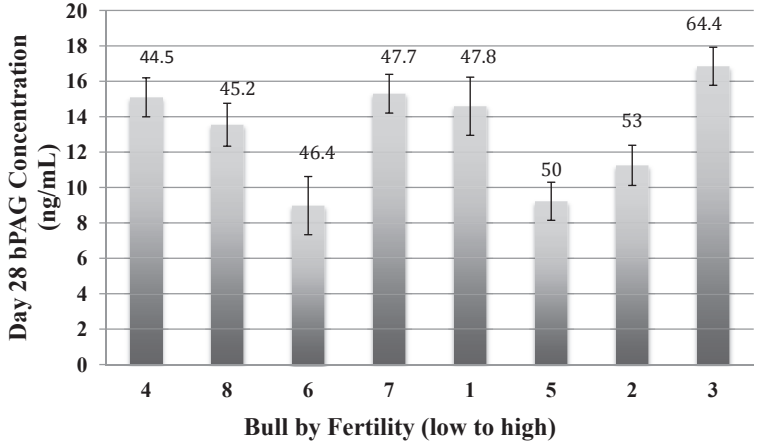

Fig. 6. Serum concentrations of bPAGs on Day 28 of gestation from cows with pregnancies sired by sires 1 to 8 . Although there was variation in the pregnancy rate after TAI among sires $(44 \%-64 \%)$, there was no linear relationship between the pregnancy rate by sire and circulating concentrations of bPAGs. However, there were significant differences in circulating concentrations of bPAGs among sires.

less than $0.72 \mathrm{ng} / \mathrm{mL}$ (minimal detectable level, $0.28 \mathrm{ng} / \mathrm{mL}$ ) was $95 \%$ accurate in predicting embryonic mortality (between Days 28 and 100) at Day 28 of gestation. In addition, P4 concentrations were not significantly associated with bPAG in circulation or predictive of late embryonic mortality.

A subset of cows in this experiment $(\mathrm{n}=720$; pregnant at Day 30, $\mathrm{n}=396$ ) were evaluated for a sire effect on bPAG concentrations on Day 30 of gestation. Although there was variation in the conception rate after TAI among sires (44\%$64 \%)$, there was no linear relationship between the pregnancy rate by sire and circulating concentrations of bPAGs (Fig. 6). However, there were significant differences in circulating concentrations of bPAGs among sires. There were 39 cows that established a pregnancy after TAI and had a viable embryo on Day 28 of gestation but failed to maintain pregnancy until Day 100 of gestation. Three sires in this experiment accounted for more than $70 \%$ of the late embryonic mortality. After removing all cows that lost a

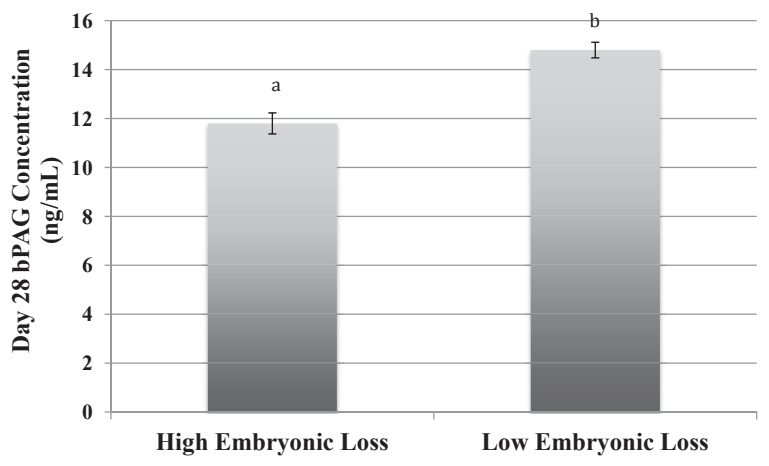

Fig. 7. Serum concentrations of bPAGs on Day 28 of gestation between sires that resulted in high embryonic loss and sires that resulted in low embryonic loss. After removing all cows that lost a pregnancy after Day 28 from the data set, the sires with the highest incidence of late embryonic mortality also were the sires with pregnancies that produced significantly $(P<0.05)$ lower maternal circulating concentrations of bPAGs on Day 28 of gestation compared with the remaining sires that had pregnancies having low embryonic mortality. a,b denote a significant difference. 


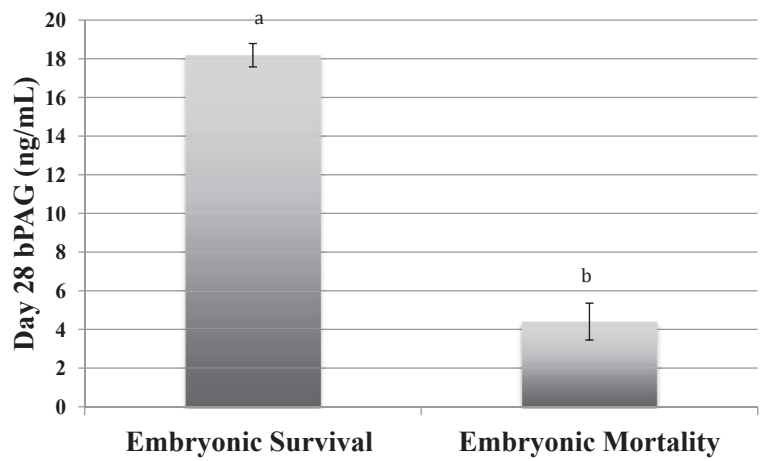

Fig. 8. Serum concentrations of bPAGs (mean \pm SEM) in postpartum primiparous Nelore beef cows that received TAI on Day 0 and had a viable embryo on Day 28 of gestation $(n=303)$ and either maintained (embryonic survival; $n=285)$ or experienced embryonic mortality $(n=18)$. Nelore beef cows that experienced late embryonic mortality by Day 100 of gestation had decreased $(\mathrm{P}<0.05)$ circulating concentrations of bPAGs on Day 28 compared with cows that maintained an embryo until Day 100. a,b denote a significant difference.

pregnancy after Day 28, the three sires with the highest incidence of late embryonic mortality were the sires whose pregnancies produced significantly $(\mathrm{P}<0.05$; Fig. 7) lower maternal circulating concentrations of bPAGs on Day 28 of gestation compared with the five remaining sires with pregnancies that experienced lower embryonic mortality.

\subsection{Experiment 3}

Primiparous Nelore beef cows underwent pregnancy diagnosis at Day 30 of gestation and the average bPAG concentration for all pregnant cows was $17.42 \pm 10.80$ $\mathrm{ng} / \mathrm{mL}$ ( $\mathrm{n}=303$; mean $\pm \mathrm{SD}$ ). As observed in experiment 2 , there was a significant difference in Day 30 bPAG concentrations between cows that successfully established and maintained ( $\mathrm{n}=285 ; 18.18 \pm 0.61 \mathrm{ng} / \mathrm{mL}$; mean \pm SEM) a pregnancy compared with those that established and failed

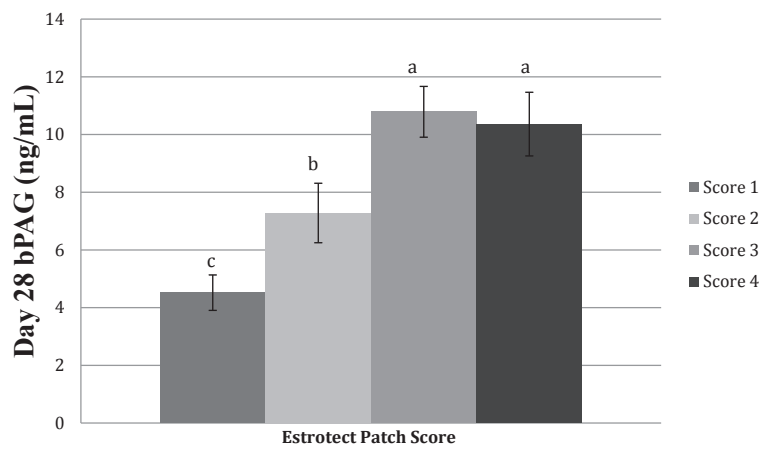

Fig. 9. Serum concentrations of bPAGs (mean \pm SEM) in postpartum primiparous Nelore beef cows that received TAI on Day 0 and had a viable embryo on Day 28 with different levels of Estrotect patch activation on Day 0 ( 0 , lost patch; $1,<25 \%$ activated; $2,<50 \%$ activated; $3,<75 \%$ activated; and $4,>75 \%$ activated). As intensity of estrus expression increased, as determined by Estrotect patch score at TAI, there was a significant increase in circulating bPAG concentrations on Day 28. a,b denote a significant difference. to maintain a pregnancy $(\mathrm{n}=18 ; 4.41 \pm 0.95 \mathrm{ng} / \mathrm{mL}$; mean \pm SEM; $\mathrm{P}<0.05$; Fig. 8). In addition, as the intensity of estrus expression increased, as determined by Estrotect patch score at TAI, there was a significant increase in circulating bPAG concentrations on Day 28 (Fig. 9). The cutoff concentration of bPAGs developed in experiment 2 $(0.72 \mathrm{ng} / \mathrm{mL})$ was $95 \%$ accurate in predicting cows that would experience embryonic mortality in experiment 3 . No cows that actually maintained pregnancy fell below the cutoff value for prediction of embryonic mortality. However, on the prediction of embryonic survivability, we were not as successful. On the basis of the cutoff value of $7.9 \mathrm{ng} / \mathrm{mL}$ from experiment 2, five cows that ended up undergoing embryonic mortality would have been predicted to maintain pregnancy.

\section{Discussion}

Bovine PAGs are detected in the maternal circulation beginning around Days 24 to 26 after insemination [18,23] and may serve as a marker for placental function [17]. Bovine PAGs were identified by multiple groups after their purification from placental extracts and their detection in the maternal circulation [26-30]. From that time, the focus of bPAG research has centered on the development of accurate assays for detecting bPAGs in blood and milk for the purpose of pregnancy diagnosis. In the present study, bPAGs were 96\% accurate in diagnosing pregnancy in $B$ indicus (Nelore) beef cows suggesting that bPAGs can work in crosses of subspecies (B taurus $\times B$ indicus). Currently, there are three commercially based assay platforms that use bPAGs for diagnosis of pregnancy in cattle either by blood or milk [31], and all have been reported to accurately diagnose pregnancy. The assay platform used in these experiments represents the commercially available test; however, it provides quantitative-based measurements of PAG.

Reports of late embryonic and/or fetal mortality in cattle range in the literature from 3\% to $40 \%$ depend on the cow type and location $[4-9,11]$. In the present study, the incidence of late embryonic mortality was $\sim 11 \%$ and $6 \%$ for experiments 2 and 3, respectively. The increased incidence of late embryonic mortality in experiment 2 was not surprising because multiparous cows have been shown to have increase late embryonic mortality compared with younger cattle [6,32].

The exact mechanisms that lead to late embryonic mortality have been poorly characterized due in part to the need for a model to identify those cattle that will maintain or not maintain a pregnancy [33]. Multiple reports have demonstrated that circulating concentrations of bPAGs may be associated with late embryonic mortality in cattle [16-18,34,35]; however, other reports have demonstrated no such association [36]. In B taurus beef cattle (Angus, Hereford, and so forth) undergoing both TAI and embryo transfer (ET), bPAG concentrations at Days 28 to 30 of gestation have been shown to be significantly increased in cows establishing and successfully maintaining a pregnancy until Days 60 to 72 of gestation compared with those that establish, but do not maintain, a pregnancy during that time period $[17,18]$. Furthermore, data in dairy cows 
showed that an increase in circulating bPAG concentrations at Days 28 to 30 was associated with pregnancy success $[16,19,35,37]$. Similar results have been shown in sheep pregnancy too [38]. However, there is conflicting data to suggest that bPAGs around Day 30 of gestation are not predictive of late embryonic mortality in high producing dairy cattle [36]. In both the beef studies mentioned previously, along with the dairy studies published by Thompson et al. [19] and Pohler et al. [35], the assay platforms used in those experiments were very similar, in that they used the exact same monoclonal-based sandwich ELISA validated by Green et al. [22]. These data suggest that the bPAG assay platform has the potential to have a major impact on the usefulness of bPAG measurements for diagnosing pregnancy and predicting late embryonic mortality.

In the present study, we aimed to develop a cutoff model by using the same sandwich ELISA platform that has shown utility in previous reports [18,22,23]. In this experiment similar results were observed. Cows undergoing late embryonic mortality between Days 28 and 100 of gestation had significantly decreased circulating concentrations of bPAGs at Day 28 of gestation compared with cows that successfully maintain a pregnancy. In addition, on the basis of the ROC curves and positive and negative predictive value analysis, we were able to determine a circulating concentration of bPAG at Day 28 of gestation that was predictive of embryonic mortality or survivability. Previous studies have shown associations between bPAG concentrations and late embryonic mortality; however, this model has allowed for prediction of pregnancy success during Days 28 to 100 of gestation. In experiment 3, this model was tested in a separate set of cows to validate its ability to detect late embryonic mortality. In primiparous Nelore beef cows, the model was 95\% accurate in predicting late embryonic mortality for a concentration less than $0.72 \mathrm{ng} / \mathrm{mL}$; however, it was not 95\% accurate in predicting embryonic maintenance. One possible explanation for this is that primiparous cows were shown in experiment 2 to have significantly increased circulating concentrations of bPAGs at Day 28 of gestation, which could explain the higher cutoff value for predicting embryonic survivability although primiparous cows were included in the original model construction in experiment 2. Another possible explanation is that bPAGs have been shown to be only predictive of pregnancy loss between Days 28 and 40 of gestation [18]; therefore, evaluating embryonic loss from Days 28 to 100 of gestation may encompass too much time. Indeed, Pohler et al. [35] suggest that bPAGs are really only predictive of embryonic mortality between Days 28 and 45 of gestation and do not take into account the possibility of ovarian failure or other types of pregnancy loss that may occur after Day 45 of gestation.

Circulating concentrations of bPAGs have been reported to increase in maternal circulation around Day 24 of gestation until about Day 36 in $B$ taurus cattle and subsequently decrease until about Day 60 of gestation; circulating concentrations of bPAGs then begin to increase again between Days 60 and 90, and they steadily rise throughout gestation until reaching a peak around the time of parturition [18]. In experiment 1 , a similar rise in bPAGs early in gestation was observed in the $B$ indicus cows used in this study. Although there is a large transient rise in bPAGs during early gestation, no clear function has been identified for these proteins; however, many correlations have been reported with circulating concentrations of bPAGs. Pregnancy status and stage, breed, parity of dam, fetal sex and number, fetal birth weight, placental weight, sire, and many more have been shown to be associated to some degree with bPAG concentrations [18,39-41]. In the present study, circulating concentrations of bPAG at Day 28 were influenced by parity of the dam, sire, and breed. In a recent study, Mercadante et al. [24] reported that cows with $B$ indicus genetics (similar to Nelore) had increased circulating concentrations of plasma bPAGs early in gestation. We observed similar results in the present study based on comparison of the current data with bPAG data collected at similar stages of gestation in $B$ taurus cattle. The exact cause of this increased bPAG concentration early in gestation is not clear; however, Mercadante et al. [24] also reported differences in fetal size and growth rate. Interestingly, parity of the cow also had a large effect on circulating bPAG concentration on Day 28 of gestation independent of overall body weight, which is a good measure of overall blood volume. Similar results have been shown by Kill et al. [32], which reported that $B$ taurus heifers had significantly higher circulating bPAG concentrations compared with mature cows. These data suggest that it is not a simple blood dilution effect and that some other mechanism is taking place in these younger animals. Potential explanations could be the half-life of bPAGs in those individual types of animals, the ability of binucleate cells to secrete products into the maternal circulation or maybe even the function or role that bPAGs are playing in these younger animals.

Limited data have been reported on sire effects on bPAG concentrations early in gestation; however, on the basis of the large influence that the sire plays in placental development, we were interested in examining this relationship. Overall, we saw no relationship between circulating concentrations of bPAGs and sire fertility, but there was a large amount of variation across sires and bPAG production. In addition, of eight sires tested three accounted for $70 \%$ of the late embryonic mortality reported in the subset of cows in experiment 2. Surprisingly, after removing all the cows that underwent late embryonic mortality after Day 28 from the analysis, those three sires exhibited significantly decreased circulating concentrations of bPAG compared with the other five sires in the study. Taken together, these data suggest that the sire does influence binucleate cell products, such as bPAGs. Indeed, circulating amounts of bPAG may serve as a novel tool for identifying low fertility sires.

Estrus expression at the time of insemination or ET has been directly correlated with pregnancy success in both beef and dairy cattle $[17,42,43]$. Preovulatory estradiol coordinates a number of physiological events that directly affect pregnancy establishment and maintenance including gamete transport and preparation of the uterine environment [15]. In beef cattle, Perry et al. [17,43] reported that beef heifers and cows exhibiting estrus within 24 hours of TAI have greater fertility compared with cows that do not exhibit standing estrus. In addition, increased preovulatory concentrations of estradiol and increased postovulatory progesterone production were observed with increased 
pregnancy success $[17,43]$. In a recent study by Pereira et al. [42], lactating dairy cows undergoing TAI or ET had increased fertility and decreased embryonic morality if they exhibited estrus versus those that did not exhibit estrus. Furthermore, lactating dairy cows that experienced pregnancy loss had decreased circulating concentrations of bPAGs early in gestation [35], similar to the present study. In the present study, there was an increase in bPAG concentrations on Day 28 of gestation when comparing Estrotect patch scores at TAI (Day 0). Surprisingly, results of previous work have not reported an association with preovulatory and/or postovulatory estradiol or progesterone production with bPAG production early in gestation [18]. Thus, the current data suggest that cows that exhibit estrus and conceive have increased circulating concentrations of bPAGs on Day 28 and increased likelihood of pregnancy success compared with pregnant cows that did not express estrus at TAI. Future experiments are needed in this area to truly understand this relationship and potential mechanism that is underlying this increase in bPAG production.

\subsection{Conclusions}

Bovine PAG concentrations increased in circulation on Day 24 of gestation and were successful in diagnosing pregnancy in postpartum Nelore cows. Multiple factors such as parity status and sire were shown to effect circulating concentrations of bPAG at Day 28. Furthermore, bPAGs on Day 28 of gestation were $95 \%$ accurate in predicting embryonic mortality during Days 28 to 100 of gestation, which provides a novel model for detecting late embryonic mortality in cattle. This tool could eventually be used to help dissect the physiological and molecular mechanisms that are involved in late embryonic mortality.

\section{Acknowledgments}

The authors would like to acknowledge the Food for the 21st Century Reproductive Biology cluster and University of Missouri Research Board for financial support. In addition, we would like to thank Tina Egen, Felipe Dantas and Shannon Davies for their technical help with these experiments. The authors would also like to thank ESTROTECT, Inc. (Spring Valley, WI) for their donation of Estrotect heat detector patches used in these experiments.

\section{References}

[1] Diskin MG, Morris DG. Embryonic and early foetal losses in cattle and other ruminants. Reprod Domest Anim 2008;43(Suppl. 2): 260-7.

[2] Ayalon N. A review of embryonic mortality in cattle. J Reprod Fertil 1978;54:483-93.

[3] Sreenan J, Diskin M. The extent and timing of embryonic mortality in the cow. Embryonic mortality in farm animals. Springer, BrusselsLuxembourg; 1986. p. 1-11.

[4] Cartmill JA, El-Zarkouny SZ, Hensley BA, Lamb GC, Stevenson JS Stage of cycle, incidence, and timing of ovulation, and pregnancy rates in dairy cattle after three timed breeding protocols. J Dairy Sci 2001:84:1051-9.

[5] Cartmill JA, El-Zarkouny SZ, Hensley BA, Rozell TG, Smith JF, Stevenson JS. An alternative AI breeding protocol for dairy cows exposed to elevated ambient temperatures before or after calving or both. J Dairy Sci 2001;84:799-806.
[6] Lamb GC. Reproductive real-time ultrasound technology: an application for improving calf crop in cattle operations. In: Fields MJ, Sand RS, Yelich JV, editors. Factors affecting calf crop: biotechnology of reproduction. Boca Raton, FL: CRC Press; 2002. p. 235-53.

[7] Silke V, Diskin MG, Kenny DA, Boland MP, Dillon P, Mee JF, et al. Extent, pattern and factors associated with late embryonic loss in dairy cows. Anim Reprod Sci 2002;71:1-12.

[8] Stevenson JS, Lamb GC, Johnson SK, Medina-Britos MA, Grieger DM, Harmoney KR, et al. Supplemental norgestomet, progesterone, or melengestrol acetate increases pregnancy rates in suckled beef cows after timed inseminations. J Anim Sci 2003;81:571-86.

[9] Vasconcelos JLM, Silcox RW, Lacerda JA, Pursley JR, Wiltbank MC. Pregnancy rate, pregnancy loss, and response to heat stress after AI at 2 different times from ovulation in dairy cows. Biol Reprod 1997; 56:140.

[10] Pereira MH, Cooke RF, Alfieri AA, Vasconcelos JL. Effects of vaccination against reproductive diseases on reproductive performance of lactating dairy cows submitted to AI. Anim Reprod Sci 2013;137: 156-62.

[11] Aono FH, Cooke RF, Alfieri AA, Vasconcelos JL. Effects of vaccination against reproductive diseases on reproductive performance of beef cows submitted to fixed-timed AI in Brazilian cow-calf operations. Theriogenology 2013;79:242-8.

[12] Spencer TE, Johnson GA, Bazer FW, Burghardt RC. Fetal-maternal interactions during the establishment of pregnancy in ruminants. Soc Reprod Fertil Suppl 2007;64:379-96.

[13] Spencer TE, Johnson GA, Bazer FW, Burghardt RC, Palmarini M. Pregnancy recognition and conceptus implantation in domestic ruminants: roles of progesterone, interferons and endogenous retroviruses. Reprod Fertil Dev 2006;19:65-78.

[14] Spencer TE, Sandra O, Wolf E. Genes involved in conceptusendometrial interactions in ruminants: insights from reductionism and thoughts on holistic approaches. Reproduction 2008; 135:165-79.

[15] Pohler KG, Geary TW, Atkins JA, Perry GA, Jinks EM, Smith MF. Follicular determinants of pregnancy establishment and maintenance. Cell Tissue Res 2012;349:649-64.

[16] Breukelman SP, Perenyi Z, Taverne MA, Jonker H, van der Weijden GC, Vos PL, et al. Characterisation of pregnancy losses after embryo transfer by measuring plasma progesterone and bovine pregnancyassociated glycoprotein-1 concentrations. Vet J 2012;194:71-6.

[17] Perry GA, Smith MF, Lucy MC, Green JA, Parks TE, MacNeil MD, et al. Relationship between follicle size at insemination and pregnancy success. Proc Natl Acad Sci U S A 2005;102:5268-73.

[18] Pohler KG, Geary TW, Johnson CL, Atkins JA, Jinks EM, Busch DC, et al. Circulating bovine pregnancy associated glycoproteins are associated with late embryonic/fetal survival but not ovulatory follicle size in suckled beef cows. J Anim Sci 2013;91:4158-67.

[19] Thompson IM, Cerri RL, Kim IH, Green JA, Santos JE, Thatcher WW. Effects of resynchronization programs on pregnancy per artificial insemination, progesterone, and pregnancyassociated glycoproteins in plasma of lactating dairy cows. J Dairy Sci 2010;93:4006-18.

[20] FASS. Guide for the care and use of agriculture animals in agriculture research and teaching 1999.

[21] Bellow R, Staigmiller R, Wilson J, Phelps D, Darling A. Use of bovine FSH for superovulation and embryo production in beef heifers. Theriogenology 1991;35:1069-82.

[22] Kirby CJ, Smith MF, Keisler DH, Lucy MC. Follicular function in lactating dairy cows treated with sustained-release bovine somatotropin. J Dairy Sci 1997;80:273-85.

[23] Green JA, Parks TE, Avalle MP, Telugu BP, McLain AL, Peterson AJ, et al. The establishment of an ELISA for the detection of pregnancyassociated glycoproteins (PAGs) in the serum of pregnant cows and heifers. Theriogenology 2005;63:1481-503.

[24] Mercadante PM, Waters KM, Mercadante VR, Lamb GC, Elzo MA, Johnson SE, et al. Subspecies differences in early fetal development and plasma pregnancy-associated glycoprotein concentrations in cattle. J Anim Sci 2013;91:3693-701.

[25] Robbins KR, Saxton AM, Southern LL. Estimation of nutrient requirements using broken-line regression analysis. J Anim Sci 2006; 84(Suppl.):E155-65.

[26] Butler JE, Hamilton WC, Sasser RG, Ruder CA, Hass GM, Williams RJ. Detection and partial characterization of two bovine pregnancyspecific proteins. Biol Reprod 1982;26:925-33.

[27] Mialon MM, Camous S, Renand G, Martal J, Menissier F. Peripheral concentrations of a $60-\mathrm{kDa}$ pregnancy serum protein during gestation and after calving and in relationship to embryonic mortality in cattle. Reprod Nutr Dev 1993;33:269-82. 
[28] Sasser RG, Ruder CA, Ivani KA, Butler JE, Hamilton WC. Detection of pregnancy by radioimmunoassay of a novel pregnancy-specific protein in serum of cows and a profile of serum concentrations during gestation. Biol Reprod 1986;35:936-42.

[29] Zoli AP, Beckers JF, Wouters-Ballman P, Closset J, Falmagne P, Ectors F. Purification and characterization of a bovine pregnancyassociated glycoprotein. Biol Reprod 1991;45:1-10.

[30] Zoli AP, Guilbault LA, Delahaut P, Ortiz WB, Beckers JF. Radioimmunoassay of a bovine pregnancy-associated glycoprotein in serum: its application for pregnancy diagnosis. Biol Reprod 1992; 46:83-92.

[31] Leblanc SJ. Short communication: field evaluation of a pregnancy confirmation test using milk samples in dairy cows. J Dairy Sci 2013; 96:2345-8.

[32] Kill LK, Pohler KG, Perry GA, Smith MF. Serum bovine pregnancy associated glycoproteins and progesterone in beef heifers that experienced late embryonic/fetal mortality. J Anim Sci Midwest Meetings. 2013.

[33] Pohler KG, Green JA, Geary TW, Peres RF, Pereira MH, Vasconcelos JL, et al. Predicting embryo presence and viability. Adv Anat Embryol Cell Biol 2015;216:253-70.

[34] Humblot P. Use of pregnancy specific proteins and progesterone assays to monitor pregnancy and determine the timing, frequencies and sources of embryonic mortality in ruminants. Theriogenology 2001;56:1417-33.

[35] Pohler KG, Pereira MH, Lopes FR, Lawrence JC, Keisler DH, Smith MF, et al. Circulating concentrations of bovine pregnancy-associated glycoproteins and late embryonic mortality in lactating dairy herds. J Dairy Sci 2016;99:1584-94.

[36] Ricci A, Carvalho PD, Amundson MC, Fourdraine RH, Vincenti L, Fricke PM. Factors associated with pregnancy-associated glycoprotein (PAG) levels in plasma and milk of Holstein cows during early pregnancy and their effect on the accuracy of pregnancy diagnosis. J Dairy Sci 2015;98:2502-14.

[37] Humblot F, Camous S, Martal J, Charlery J, Jeanguyot N, Thibier M, et al. Pregnancy-specific protein B, progesterone concentrations and embryonic mortality during early pregnancy in dairy cows. J Reprod Fertil 1988;83:215-23.

[38] Wallace JM, Aitken RP, Cheyne MA, Humblot P. Pregnancy-specific protein $\mathrm{B}$ and progesterone concentrations in relation to nutritional regimen, placental mass and pregnancy outcome in growing adolescent ewes carrying singleton fetuses. J Reprod Fertil 1997; 109:53-8.

[39] Lobago F, Bekana M, Gustafsson H, Beckers JF, Yohannes G, Aster Y, et al. Serum profiles of pregnancy-associated glycoprotein, oestrone sulphate and progesterone during gestation and some factors influencing the profiles in Ethiopian Borana and crossbred cattle. Reprod Domest Anim 2009;44:685-92.

[40] Patel OV, Sulon J, Beckers JF, Takahashi T, Hirako M, Sasaki N, et al. Plasma bovine pregnancy-associated glycoprotein concentrations throughout gestation in relationship to fetal number in the cow. Eur J Endocrinol 1997;137:423-8.

[41] Wallace RM, Pohler KG, Smith MF, Green JA. Placental PAGs: gene origins, expression patterns, and use as markers of pregnancy. Reproduction 2015;149:R115-26.

[42] Pereira M, Wiltbank M, Vasconcelos J. Expression of estrus improves fertility and decreases pregnancy losses in lactating dairy cows that receive artificial insemination or embryo transfer. J Dairy Sci 2015; 99:2237-47.

[43] Perry GA, Smith MF, Roberts AJ, MacNeil MD, Geary TW. Relationship between size of the ovulatory follicle and pregnancy success in beef heifers. J Anim Sci 2007;85:684-9. 